\title{
Long-term aerosol-mediated changes in cloud radiative forcing of deep clouds at the top and bottom of the atmosphere over the Southern Great Plains
}

\author{
Hongru Yan ${ }^{1,2}$, Zhanqing $\mathrm{Li}^{2,3}$, Jianping Huang ${ }^{1}$, Maureen $\mathrm{Cribb}^{2}$, and Jianjun Liu ${ }^{2}$ \\ ${ }^{1}$ Key Laboratory for Semi-Arid Climate Change of the Ministry of Education, College of Atmospheric Sciences, Lanzhou \\ University, Lanzhou 730000, China \\ ${ }^{2}$ Department of Atmospheric and Oceanic Science and ESSIC, University of Maryland, College Park, Maryland 20742, USA \\ ${ }^{3}$ College of Global Change and Earth System Sciences, Beijing Normal University, Beijing10087, China
}

Correspondence to: Z. Li (zli@atmos.umd.edu)

Received: 13 December 2013 - Published in Atmos. Chem. Phys. Discuss.: 20 February 2014

Revised: 17 May 2014 - Accepted: 31 May 2014 - Published: 16 July 2014

\begin{abstract}
Aerosols can alter the macro- and micro-physical properties of deep convective clouds (DCCs) and their radiative forcing (CRF). This study presents what is arguably the first long-term estimate of the aerosol-mediated changes in CRF (AMCRF) for deep cloud systems derived from decade-long continuous ground-based and satellite observations, model simulations, and reanalysis data. Measurements were made at the US Department of Energy's Atmospheric Radiation Measurement Program's Southern Great Plains (SGP) site. Satellite retrievals are from the Geostationary Operational Environmental Satellite. Increases in aerosol loading were accompanied by the thickening of DCC cores and the expansion and thinning of anvils, due presumably to the aerosol invigoration effect (AIV) and the aerosol microphysical effect. Meteorological variables dictating these cloud processes were investigated. Consistent with previous findings, the AIV is most significant when the atmosphere is moist and unstable with weak wind shear. Such aerosol-mediated systematic changes in DCC core thickness and anvil size alter $\mathrm{CRF}$ at the top of atmosphere (TOA) and at the surface. Using extensive observations, $\sim 300$ DCC systems were identified over a 10 years period at the SGP site (2000-2011) and analyzed. Daily mean AMCRF at the TOA and at the surface are $29.3 \mathrm{~W} \mathrm{~m}^{-2}$ and $22.2 \mathrm{~W} \mathrm{~m}^{-2}$, respectively. This net warming effect due to changes in DCC microphysics offsets the cooling resulting from the first aerosol indirect effect.
\end{abstract}

\section{Introduction}

Aerosols can alter the radiative energy of the earth's surfaceatmosphere system by directly attenuating solar radiation and/or by indirectly modifying cloud macro-physical (areal coverage, structure, altitude) and microphysical properties (droplet size, phase) in many different ways. Studies have shown that high aerosol loadings can produce a large number of tiny cloud droplets (Twomey, 1977), which suppress the warm rain-forming process through indirect effects (Albrecht, 1989). This allows more cloud particles to ascend above the freezing level and convert to ice hydrometeors. During this ice process, the release of more latent heat invigorates the vertical development of clouds and enhances precipitation and lighting (Rosenfeld et al., 2008a; Yuan et al., 2011). This effect is the so-called aerosol invigoration effect (AIV), which was first noted by Williams et al. (2002) who found that aerosols could fuel cloud vertical development and lift cloud-top heights. This was reinforced by an airborne experiment conducted in the Amazon (Andreae et al., 2004). The AIV is also associated with the expansion of cloud anvil extent (Koren et al., 2010a). Such aerosolmediated changes in cloud parameters alter cloud radiative forcing (CRF), which is a component of aerosol radiative forcing (ARF). To differentiate it from ARF exerted under clear-sky conditions, it is often referred to as aerosol indirect forcing or the aerosol indirect effect. It is called the aerosolmediated CRF (AMCRF) in this study. Among the aerosolinduced changes in radiative energy (IPCC, 2013), AMCRF 
has the largest uncertainty because of the poor understanding of the mechanisms behind it, as reviewed recently by Rosenfeld et al. (2013). To date, only radiative forcing due to the first aerosol indirect effect has been considered in most climate models. Using observations to quantify the AIV and its impact on climate is very important for climate modeling and climate prediction.

The AIV has been demonstrated during several aircraft field campaigns, such as those studying tropical clouds in the Amazon (Andreae et al., 2004), hail storms in Argentina (Rosenfeld et al., 2006), winter storms in California (Rosenfeld et al., 2008a), and summer monsoon clouds in India (Freud and Rosenfeld, 2012). Satellite measurements have also been used to quantify the AIV over the Amazon basin (Lin et al., 2006), over the Atlantic Ocean (Koren et al., 2005; Storer et al., 2014), and over the entire global tropics (Niu and Li, 2012). The AIV occurs only under certain microphysical, dynamic and thermodynamic conditions (Khain and Pokrovsky, 2004; Khain et al., 2004, 2005, 2008; Wang, 2005; Seifert and Beheng, 2006; van den Heever et al., 2006; Fan et al., 2007, 2009). Rosenfeld et al. (2008b) postulated that the AIV is most significant for deep convective clouds (DCCs) with warm cloud bases and cold cloud tops. This was confirmed by an analysis of 10 years of observation data collected at the Atmospheric Radiation Measurement (ARM) Southern Great Plains (SGP) site (Li et al., 2011). The modeling study of Fan et al. (2009) further showed that weak wind shear and a moist environment favors the AIV. The expansion of anvil clouds associated with DCCs can induce positive radiative forcing during the invigoration process, while the thickening of the cores of DCCs may lead to cooling, rendering an uncertain net radiative effect (Koren et al., 2010a; Fan et al., 2012). The diurnal variation of DCCs is a key factor dictating the net effect because the shortwave cooling effect is most prominent at noon, and is nil at night.

Following $\mathrm{Li}$ et al. (2011) who revealed the impact of aerosols on cloud vertical development and precipitation frequency using ground-based measurements, this study aims to (1) identify factors governing the AIV and AIV-induced changes in CRF under various thermodynamic and dynamic environmental conditions, and (2) estimate the long-term AIV-induced changes in the CRF at the top of the atmosphere (TOA) and at the surface using a combination of geostationary satellite retrievals and ground-based observations made at the US Department of Energy's Atmospheric Radiation Measurement Program's Southern Great Plains (SGP) site.

A brief description of various data sets used in this study is presented in Sect. 2, along with a description of the procedure used to calculate AMCRF. Section 3 shows the aerosol effect on DCC properties, such as cloud-top height, size of the cloud anvil and convective core, and radiative forcing arising from changes in cloud properties induced by the AIV. Section 4 summarizes the findings.

\section{Data and methodology}

\subsection{Surface observations}

The SGP site was the first field observation site established by the US Department of Energy's Atmospheric Radiation Measurement Program (Stokes and Schwartz, 1994; Ackerman and Stokes, 2003) and has collected continuous measurements of extensive aerosol, cloud and meteorological variables for the past 25 years. This study uses data from 2000 to 2011 and is focused on convective clouds, which are more susceptible to aerosols (Tao et al., 2012). Condensation nuclei $(\mathrm{CN})$ number concentration measured by a TSI model 3010 condensation particle counter is used as a proxy for aerosols. Cloud condensation nuclei (CCN) would be a better proxy, but there are not as many measurements available at the SGP site and many gaps in the times series are present due to the more delicate nature of the measurement technique. Relative to the more widely available aerosol optical depth (AOD), CN has a closer relationship with cloud droplets.

Cloud base and top boundary information are inferred from a suite of active sensors including the millimeter wavelength cloud radar (MMCR), the ceilometer, and the micropulse lidar (MPL) (Clothiaux et al., 2000). The cloudtop height might be blurred under heavy rain condition as the radar signal would be attenuated, but they are also valid for the majority of DCCs that do not rain. Combined with temperature profiles from the European Centre for Medium-Range Weather Forecast (ECMWF) diagnostic analyses, cloud base and top temperatures can be generated. The cloud-top temperature (CTT) helps identify the phase of a cloud and the cloud-base temperature (CBT) indicates the likelihood of interactions between clouds and aerosols that are located chiefly in the planetary boundary layer. As in Li et al. (2011), clouds with CBT greater than $15^{\circ} \mathrm{C}$ are selected. This maximizes the likelihood that the $\mathrm{CN}$ measured on the ground will likely have an impact on cloud properties. ARM data, sampled every $10 \mathrm{~s}$, are averaged over 30 min intervals in this study. This choice of averaging interval is discussed in Sect. 2.3.

Other parameters from the ECMWF diagnostic analyses used in the study include vertical velocity, wind shear, and convective available potential energy (CAPE). AOD used in radiative transfer calculations under clear-sky conditions is retrieved from multi-filter rotating shadowband radiometer (MFRSR) measurements (Min and Harrison, 1996; Min et al., 2004, 2008; Wang and Min, 2008). Columnintegrated amounts of water vapor (PWV) and the cloud liquid water path (LWP) are retrieved from microwave radiometer (MWR) measurements of brightness temperatures at $23.8 \mathrm{GHz}$ and $31.4 \mathrm{GHz}$ (Liljegren, 1999). Fractional sky cover retrievals from the total sky imager (TSI) are also used. Hemispheric radiative fluxes measured by pyranometers and pyrgeometers provide information about the radiation budget 
Table 1. Data sets used in the study.

\begin{tabular}{|c|c|c|c|}
\hline Parameters & $\begin{array}{l}\text { Temporal or spatial } \\
\text { resolution }\end{array}$ & Instrument or retrieval algorithm & Period \\
\hline $\mathrm{CN}$ concentration & $60 \mathrm{~s}$ & $\begin{array}{l}\text { TSI model } 3010 \text { condensation parti- } \\
\text { cle counter }\end{array}$ & 2000.01-2010.03 \\
\hline Cloud-top/base height & $10 \mathrm{~s}$ & $\begin{array}{l}\text { MMCR, ceilometer, MPL; Cloth- } \\
\text { iaux et al. ( } 2000)\end{array}$ & 2000.01-2010.03 \\
\hline Cloud fraction & $30 \mathrm{~s}$ & TSI & 2000.07-2010.03 \\
\hline Cloud optical depth & $60 s$ & $\begin{array}{l}\text { MFRSR; Min and Harrison (1996); } \\
\text { Min et al. (2004) }\end{array}$ & 2000.01-2010.03 \\
\hline $\begin{array}{l}\text { Cloud liquid water path } \\
\text { Column water vapor }\end{array}$ & $20 \mathrm{~s}$ & MWR (Liljegren, 1999) & $2000.01-2010.03$ \\
\hline $\begin{array}{l}\text { Cloud fraction } \\
\text { Cloud-top/base height }\end{array}$ & $4 \mathrm{~km} / 30 \mathrm{~min}$ & $\begin{array}{l}\text { GOES VISST algorithm (Minnis et } \\
\text { al., 2011) }\end{array}$ & $\begin{array}{l}2000.01-2005.09 \\
2006.05-2010.03\end{array}$ \\
\hline $\begin{array}{l}\text { Cloud optical depth } \\
\text { Cloud effective radius } \\
\text { Cloud liquid water path } \\
\text { TOA radiation fluxes }\end{array}$ & & $\begin{array}{l}\text { GOES NB-BB conversion algo- } \\
\text { rithm; Minnis et al. (1995) }\end{array}$ & \\
\hline Precipitation & $60 \mathrm{~s}$ & Rain gauge & 2000.01-2010.03 \\
\hline $\begin{array}{l}\text { Vertical velocity } \\
\text { CAPE } \\
\text { Wind shear }\end{array}$ & $1 \mathrm{~h}$ & ECMWF diagnostic analyses & 2000.01-2010.03 \\
\hline
\end{tabular}

at the surface. Precipitation is from rain gauge measurements. Table 1 summarizes ground measurements used in this study.

\subsection{Satellite retrievals}

The Geostationary Operational Environmental Satellite (GOES) platform provides continuous pixel-level $(4 \mathrm{~km})$ cloud properties and TOA radiative fluxes. Broadband shortwave (SW) and longwave (LW) radiative fluxes at the TOA are estimated from narrowband GOES data using narrowband-to-broadband (NB-BB) conversion formulas (Minnis et al., 1995). Formula coefficients have historically been derived by regressing matched polar orbiting satellite BB fluxes or radiances with their NB counterparts from GOES. The visible infrared solar-infrared split window technique (VISST: Minnis et al., 2011; Huang et al., 2005) has been used to retrieve cloud properties at pixellevel to help infer gross features of DCCs. CTT is retrieved from VISST infrared (IR) radiances, while cloud droplet effective radius $\left(r_{\mathrm{e}}\right)$ is derived from $3.78 \mu \mathrm{m}$ radiances. Cloud optical depth $(\tau)$ is retrieved from visible reflectances. The $12.0 \mu \mathrm{m}$ channel aids in phase selection. Cloud liquid water path (LWP) is computed as $2 / 3 \cdot \tau \cdot r_{\mathrm{e}}$. Unlike single-point ground-based retrievals, satellite retrievals are available over a much larger area. The domain selected for this study is 32$42^{\circ} \mathrm{N}(\sim 1000 \mathrm{~km})$ in latitude and $105-90^{\circ} \mathrm{W}(\sim 1500 \mathrm{~km})$ in longitude. Satellite retrievals used are listed in Table 1. These satellite-based estimates are used to determine AM$\mathrm{CRF}$ at the TOA, while ground-based measurements are used for investigating the AIV and to estimate AMCRF at the surface.

\subsection{Methodology}

The study uses both ground-based and satellite measurements, which cover different spatial areas and have different temporal frequencies. Ground measurements are made continuously at the SGP site at a high frequency. Satellite observations are made over a large area around the SGP site, but not as frequently. Cloud fractions for different spatial domains centered on the SGP site were calculated from satellite retrievals and cloud frequencies for different averaging intervals were calculated from ground measurements. The optimal match is achieved when the satellite product is averaged over a $20 \mathrm{~km} \times 20 \mathrm{~km}$ area around the SGP site and when surface observations are averaged over $30 \mathrm{~min}$, centered on the satellite overpass time. Note that the spatial and temporal match between the two types of measurements depends on the cloud regime (Dong et al., 2002; Li et al., 2005; Yan et al., 2011).

\section{Results and discussion}

\subsection{The AIV}

A variety of cloud types can appear over the SGP site, which experiences large seasonal variations in temperature and humidity. Analyses of long-term cloud products from ARM measurements reveal that stratus and cirrus clouds are the major cloud types seen at the SGP site (Lazarus et 
al., 2000; Kollias et al., 2007). Cumulonimbus clouds are not frequent there. Theoretical and observation-based studies have demonstrated that the AIV is significant for mixedphase warm-based clouds (Andreae et al., 2004; Koren et al., 2005; Rosenfeld et al., 2008b; Li et al., 2011). Invigorated clouds have a greater chance of developing into DCCs by lifting cloud-top heights and expanding cloud anvil fractions (Koren et al., 2010a). Taking advantage of pixel-level cloud optical depth (COD, or $\tau$ ) from GOES retrievals, DCCs are further classified as deep convective cores (pixels with $\tau>10$ ) and anvils (pixels with $\tau<10$ ), as defined by Koren et al. (2010a). GOES data has a resolution of $4 \mathrm{~km}$ which is too coarse to resolve clouds, especially warm cumulus clouds. However, this study is concerned with large DCC systems, which are identified using ground observations. Figure 1a shows the relationship between CTT and CN concentration for single-layered clouds. In the case of a precipitating cloud layer, $\mathrm{CN}$ concentrations measured $1.5 \mathrm{~h}$ before the observed rainfall were used. During the decade-long period, the total number of matched cloudy cases identified using ground-based and GOES data is 22, 820. Of the total, 861 are single-layer clouds with CBT greater than $15^{\circ} \mathrm{C}$. The number of warm shallow clouds $\left(\mathrm{CTT}>0{ }^{\circ} \mathrm{C}\right.$ ) and mixed-phase clouds $\left(\mathrm{CTT}<-4^{\circ} \mathrm{C}\right)$ are 516 and 299 , respectively. CTT decreases from $-46.0^{\circ} \mathrm{C}$ to $-51.4^{\circ} \mathrm{C}$ as the aerosol loading increases from $1000 \mathrm{~cm}^{-3}$ to $5000 \mathrm{~cm}^{-3}$ for cases where CTT $<-4{ }^{\circ} \mathrm{C}$. The CTT for warm shallow clouds, however, show little change with increase in $\mathrm{CN}$ concentration. This finding is similar to that of $\mathrm{Li}$ et al. (2011). For mixed-phase warm-based clouds, an increase in aerosol loading reduces the size of cloud droplets. These droplets are more likely to be lifted by updrafts to become mixed-phase clouds due to buoyancy from the release of latent heat, which invigorates convection. Figure $1 \mathrm{~b}$ shows the relationship between cloud fraction and $\mathrm{CN}$ concentration for three subsets of DCCs: DCCs, DCC cores, and anvils associated with the DCCs. While DCCs and DCC core cloud fractions decrease with increasing $\mathrm{CN}$, anvil cloud fractions increase as the aerosol loading increases, consistent with statistical analyses and model simulations performed over other regions of the globe (Koren et al., 2010a; van den Heever et al., 2011).

Although aerosol particles play a key role in the formation of cloud droplets, cloud development is mainly driven by large-scale dynamic conditions. Koren et al. (2010b) used satellite data to study correlations between cloud properties and all variables from reanalysis data and found that vertical velocity and humidity are the primary meteorological controls on a cloud system. Through sensitivity studies using a cloud-resolving model, Fan et al. (2009) found that wind shear plays a dominant role in influencing the intensity of the AIV.

Li et al. (2011) examined the correlation relationships between the $\mathrm{CN}$ concentration and some meteorological variables influencing cloud development and found that they were weak. This suggests that changes in cloud properties in-
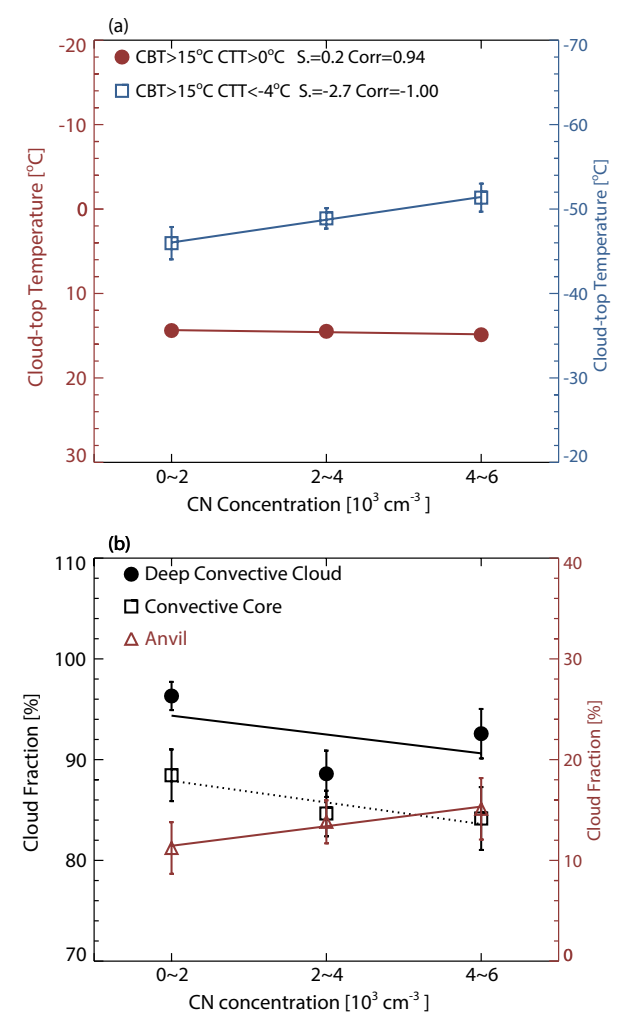

Figure 1. (a) Cloud-top temperature and (b) cloud fraction as a function of aerosol $\mathrm{CN}$ concentration.

duced by atmospheric dynamics/thermodynamics can be effectively removed by using a very large number of samples. To identify environmental factors that might affect the properties of clouds selected for this study, relationships between cloud properties and aerosol loading are analyzed according to vertical velocity (vv), CAPE, PWV and wind shear (ws). Wind shear is calculated as the maximum of horizontal wind speed $(u)$ minus the minimum of $u$ within the lowest $7 \mathrm{~km}$ of the atmosphere (Fan et al., 2009). Figure 2 shows CTT as a function of $\mathrm{CN}$ concentration for the different environmental conditions selected here. Each meteorological parameter was divided into two groups representing diametrically possible values, e.g., rising motion and subsidence for the case of vv. Each group contains approximately equal numbers of samples and enough samples to reduce the noise generated by the analyses. No matter if the environment is unstable $\left(\mathrm{vv}>0.0 \mathrm{~ms}^{-1}, \mathrm{CAPE}>500 \mathrm{Jm}^{-2}\right)$ or stable $\left(\mathrm{vv}<0.0 \mathrm{~ms}^{-1}, \mathrm{CAPE}<500 \mathrm{Jm}^{-2}\right)$, moist $(\mathrm{PWV}>5 \mathrm{~cm})$ or dry (PWV $<5 \mathrm{~cm}$ ), CTT decreases as $\mathrm{CN}$ concentration increases (Fig. 2a-c). Under unstable and/or moist conditions, increasing the aerosol concentration in mixed-phase warmbased clouds generates more latent heat which, in turn, invigorates convection. The magnitude of the slope in the CTT$\mathrm{CN}$ relationship is then larger than that under stable and/or dry conditions (Fig. $2 b$ and c). Figure $2 d$ shows that increasing the aerosol loading likely suppresses convection under 

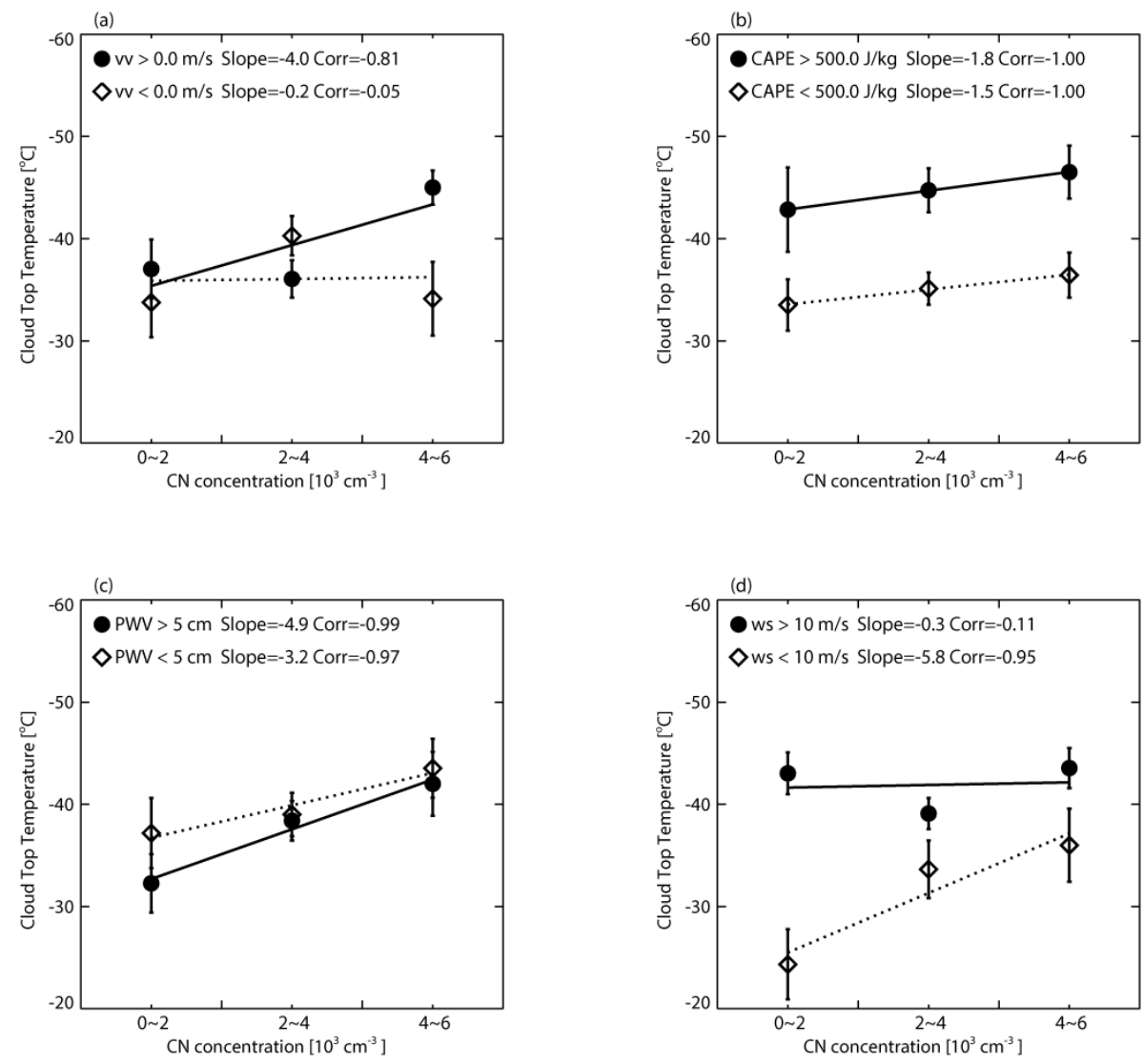

Figure 2. Cloud-top temperature as a function of aerosol CN concentration for deep convective clouds under different (a) vertical velocity (vv), (b) CAPE, (c) precipitable water vapor amount (PWV), and (d) wind shear (ws) conditions. Slopes and correlation coefficients of the different regressions are given.

strong wind shear conditions, but invigorates convection under weak wind shear conditions. Under weak wind shear conditions, the increase in condensational heating is more than the increase in evaporative cooling and/or entrainment as the aerosol load increases, leading to an increase in net latent heat release and stronger convection. With strong wind shear, the opposite holds, leading to the suppression of convection.

The above analyses together with those made in an earlier study by $\mathrm{Li}$ et al. (2011) for the same period and in the same region are consistent with the phenomenon of the AIV postulated by Rosenfeld et al. (2008). Causes for the AIV were recently revised significantly by Fan et al. (2013). While the thermodynamic role of aerosols in modulating latent heat release to fuel the development of a DCCs is still valid, it is the aerosol microphysical effect that seems to play a more important role, especially in the expansion of the anvil fraction. The extensive model simulation results obtained by Fan et al. (2013) agree well with observation-based findings, which may thus serve as another piece of evidence supporting aerosol and DCC interactions.

\subsection{Determination of AMCRF}

CRF is defined as the difference in net radiative fluxes under all-sky conditions minus those under clear-sky conditions:

$$
\mathrm{CRF}(\mathrm{SZA}, \mathrm{CN})=R_{\text {cloudy }}(\mathrm{SZA}, \mathrm{CN})
$$

$-R_{\text {clear }}(\mathrm{SZA}, \mathrm{CN})$,

where $R_{\text {cloudy }}(\mathrm{SZA}, \mathrm{CN})$ and $R_{\text {clear }}(\mathrm{SZA}, \mathrm{CN})$ are the simultaneous net radiative fluxes at the TOA and/or surface under all-sky and clear-sky conditions, respectively. SZA stands for the solar zenith angle. $R_{\text {cloudy }}(\mathrm{SZA}, \mathrm{CN})$ is directly calculated from measurements: the GOES VISST product for TOA fluxes and radiation data measured at the SGP site for surface fluxes. $R_{\text {clear }}(\mathrm{SZA}, \mathrm{CN})$ is calculated using the Santa Barbara DISORT Atmospheric Radiative Transfer (SBDART, version 2.4) model with a 4-stream discrete ordinates radiative transfer solver (Ricchiazzi et al., 1998). Inputs to the model include temperature profiles measured from atmospheric soundings and PWV retrieved from the MWR. Other model input parameters include total column amount of atmospheric ozone from the Ozone Monitoring Instrument on the Aqua platform, surface spectral albedo 

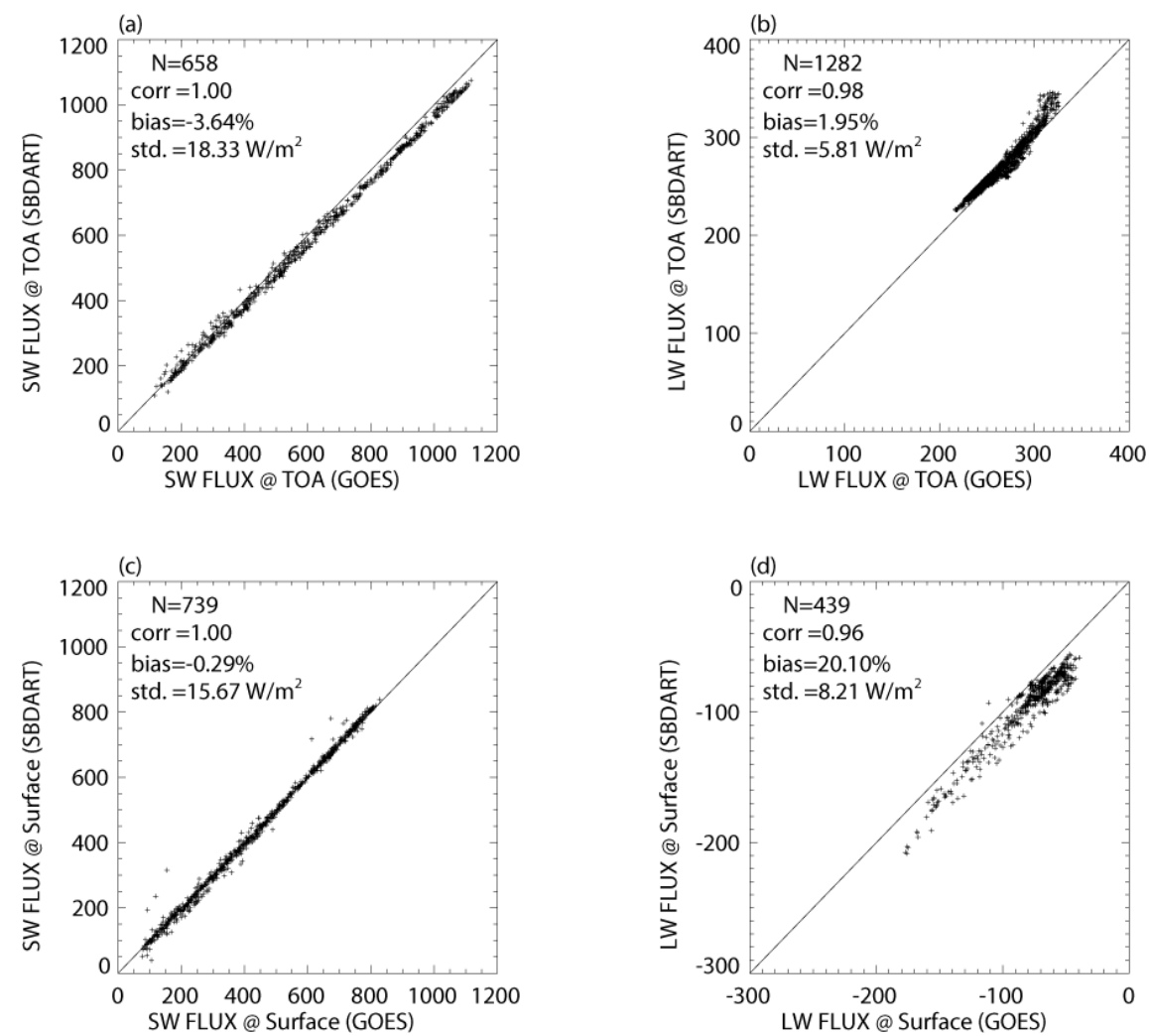

Figure 3. Santa Barbara DISORT Atmospheric Radiative Transfer (SBDART)-modeled flux as a function of satellite-retrieved flux for (a) SW fluxes at the TOA, (b) LW fluxes at the TOA, (c) SW fluxes at the surface, and (d) LW fluxes at the surface. Units are W m ${ }^{-2}$. Standard deviation, bias, correlation coefficient, and number of data points $(N)$ are given.

measured from the MFRSR installed on the 10-m tower at the SGP site, MFRSR-retrieved AOD, and surface temperature measurements from the infrared thermometer. Based on $\mathrm{CRF}(\mathrm{SZA}, \mathrm{CN})$ calculated in the first step, diurnal cycles of $\mathrm{CRF}(\mathrm{SZA}, \mathrm{CN})$ and the daily mean, $\mathrm{CRF}(\mathrm{CN})$ for each $\mathrm{CN}$ bin have been derived.

Figure 3 shows model-simulated SW and LW net radiative fluxes at the TOA as a function of GOES retrievals and ground observations made under clear-sky conditions. Cloud-free cases were identified by GOES retrievals and TSI observations during the day and by GOES retrievals only during the night. Mean biases in SW (LW) net radiative fluxes at the TOA are $-3.64 \%(1.95 \%)$. At the surface, mean biases in SW (LW) net radiative fluxes are $-0.29 \%$ (20.1\%). Overall, $R_{\text {cloudy }}(\mathrm{SZA}, \mathrm{CN}$ ) simulated using the SBDART model is in good agreement with observations. Sub-optical cirrus cloud contamination may explain the relatively poor agreement in net LW fluxes at the surface. Such clouds are very cold and emit less LW radiation.

Figure 4 shows SW, LW, and net CRF at the TOA (lefthand panels) and at the surface (right-hand panels) for DCCs as a function of SZA for different ranges of $\mathrm{CN}$ concentration and as a function of $\mathrm{CN}$ concentration. As expected, LW CRF is independent of SZA, and increases with increasing CN. In- stantaneous SW CRF is largely influenced by the intensity of solar radiation and ranges from 0 to $\sim-600 \mathrm{Wm}^{-2}$. As the $\mathrm{CN}$ range changes from $0-2000 \mathrm{~cm}^{-3}$ to $2000-4000 \mathrm{~cm}^{-3}$, a noticeable and systematic increase in the magnitude of CRF is clearly seen, despite the larger uncertainty due to the smaller number of samples for the larger $\mathrm{CN}$ range. There are much fewer data samples in the largest $\mathrm{CN}$ range bin, leading to a larger uncertainty in the estimate of CRF. The magnitude of surface SW CRF is larger than that of TOA SW CRF, while the opposite is the case for LW CRF.

Instantaneous AMCRF is defined as

$$
\mathrm{AMCRF}(\mathrm{SZA})=\mathrm{CRF}(\mathrm{SZA}, \mathrm{CN})-\mathrm{CRF}\left(\mathrm{SZA}, \mathrm{CN}_{0}\right) .
$$

In principal, $\mathrm{CN}_{0}$ should be equal to zero, which is physically impossible. So an unperturbed $\mathrm{CN}$ value representative of relatively clean conditions is used instead. Diurnal mean AMCRF is defined as

$$
\operatorname{AMCRF}=\frac{\int_{-T}^{T} \operatorname{AMCRF}(t) d t}{\int_{-T}^{T} d t}=\frac{\int_{0}^{1} \operatorname{AMCRF}(\mu) f(\mu) d \mu}{\int_{0}^{1} f(\mu) d \mu}
$$



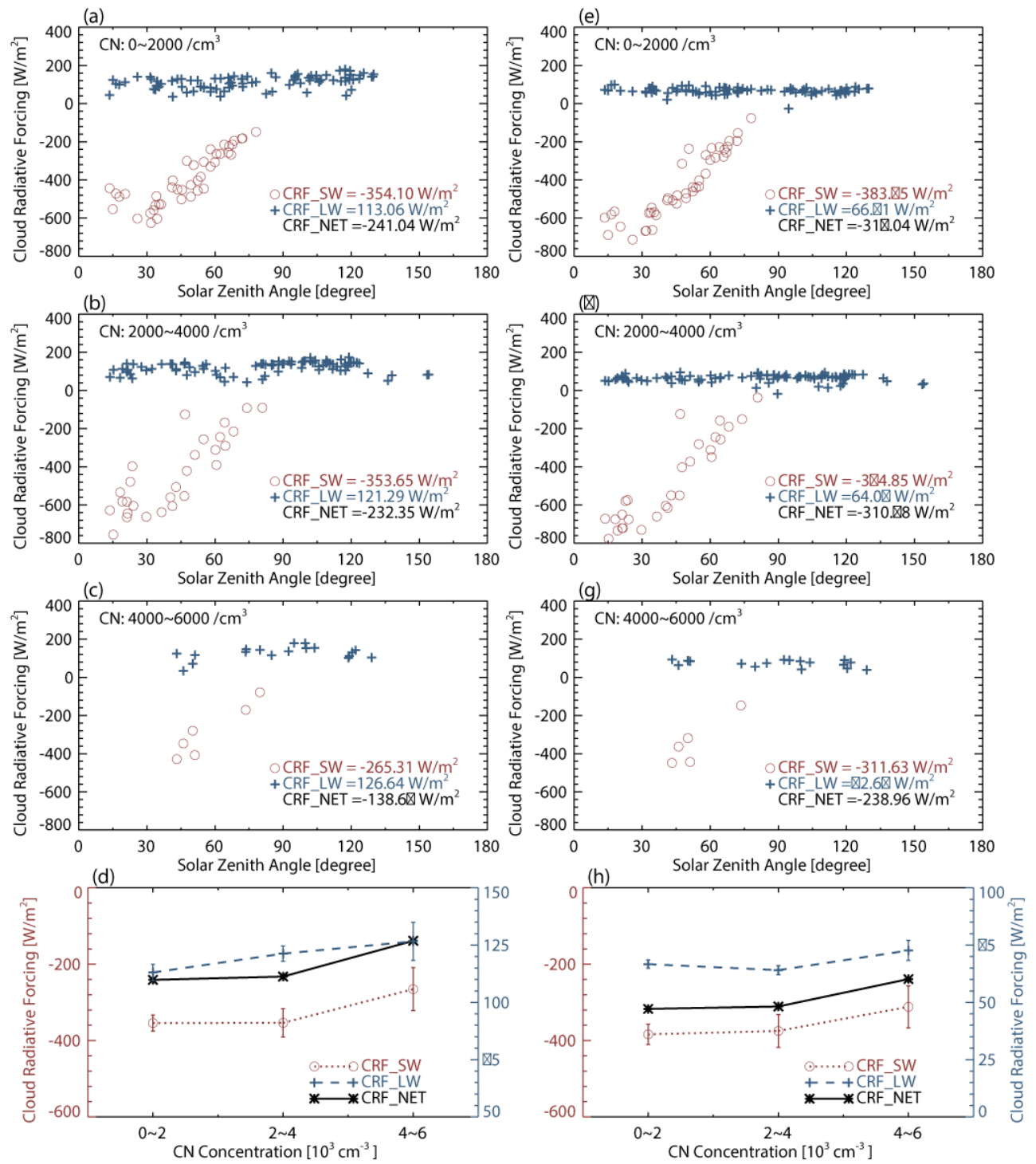

Figure 4. Deep convective cloud radiative forcing at the TOA (left-hand panels) and at the surface (right-hand panels) as a function of solar zenith angle for different ranges of $\mathrm{CN}$ concentration $(\mathbf{a}-\mathbf{c}, \mathbf{e}-\mathbf{g})$ and as a function of aerosol $\mathrm{CN}$ concentration $(\mathbf{d}, \mathbf{h})$.

$\mu=\cos (\mathrm{SZA})=\sin \varphi \sin \delta+\cos \varphi \cos \delta \cos \left(\frac{2 \pi t}{24}\right)$

$f(\mu)=\frac{d t}{d \mu}=-\frac{24}{2 \pi \sqrt{(\cos \varphi \cos \delta)^{2}-(\mu-\sin \varphi \cos \delta)^{2}}}$,

where $T$ is the half-day length which varies according to latitude and season, and $\varphi$ and $\delta$ are latitude and declination, respectively. Equations (2)-(4) are adopted from Li and Garand (1994). Note that the diurnal variation of SW CRF not only includes the effect of varying SZA, but also the diurnal changes in DCCs. The diurnally-averaged CRF in Eq. (2) is determined numerically as
$\mathrm{AMCRF}=\frac{\sum_{i=1}^{n} \operatorname{AMCRF}\left(\mu_{i}\right) f\left(\mu_{i}\right) \Delta \mu_{i}}{\sum_{i=1}^{n} f\left(\mu_{i}\right) \Delta \mu_{i}}$,

where $n$ is the number of data points in Fig. $4 \mathrm{a}-\mathrm{c}$ and eg. The discrete values of $\mu_{i}$ and $\operatorname{AMCRF}\left(\mu_{i}\right)$ at the TOA and at the surface have been substituted into these equations and the trapezoidal rule has been applied for each interval. Diurnal mean values for the individual components are given both in numbers (upper six panels) and plotted as functions of CN (lower two panels).

The daily mean TOA LW CRF increases monotonically from $113.1 \pm 3.6 \mathrm{Wm}^{-2}$ to $127.8 \pm 8.3 \mathrm{Wm}^{-2}$ as the mean $\mathrm{CN}$ concentration increases from $1000 \mathrm{~cm}^{-3}$ to $5000 \mathrm{~cm}^{-3}$. 

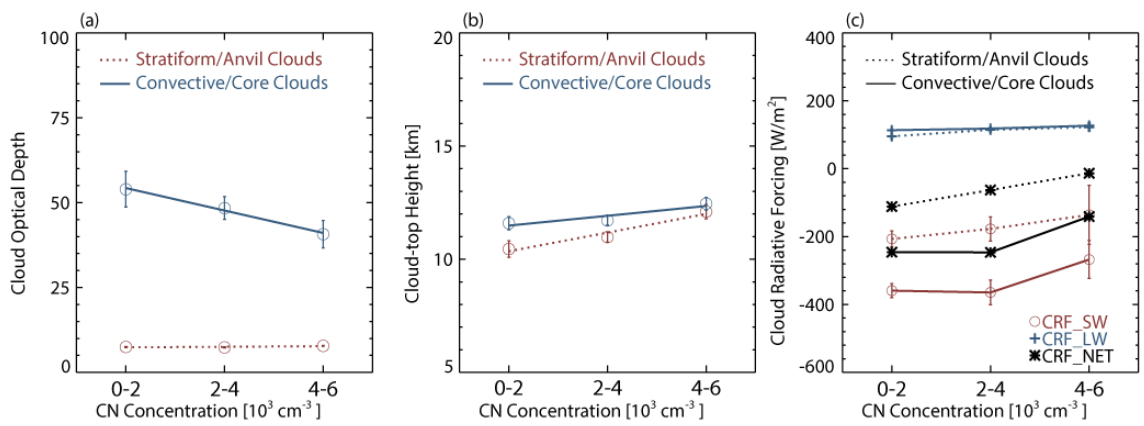

Figure 5. Deep convective cloud (a) optical depth, (b) top height, and (c) radiative forcing (SW, LW, and net) as a function of aerosol CN concentration. Solid lines are for convective cores and dotted lines represent anvils.

This is accompanied by a decrease in mean CTT from $-46.0^{\circ} \mathrm{C}$ to $-51.4^{\circ} \mathrm{C}$ (Fig. 4d). The slight enhancement of LW warming at the TOA is due to the reduction in CTT, leading to a decrease in outgoing thermal radiative fluxes. At the surface level, the daily mean LW CRF changes from $66.7 \pm 1.9 \mathrm{Wm}^{-2}$ to $72.7 \pm 4.3 \mathrm{Wm}^{-2}$ (Fig. 4h). The much smaller increase is consistent with the finding that cloud bases are much less sensitive to $\mathrm{CN}$, as shown by $\mathrm{Li}$ et al. (2011).

The daily mean TOA SW CRF remains constant $\left(\sim-354 \mathrm{~W} \mathrm{~m}^{-2}\right)$ as the mean $\mathrm{CN}$ concentration increases from $1000 \mathrm{~cm}^{-3}$ to $3000 \mathrm{~cm}^{-3}$. It then sharply increases from $-353.6 \pm 37.1 \mathrm{Wm}^{-2}$ to $-265.3 \pm 56.3 \mathrm{Wm}^{-2}$ when the $\mathrm{CN}$ concentration increases from $3000 \mathrm{~cm}^{-3}$ to $5000 \mathrm{~cm}^{-3}$. At the surface, changes in SW CRF are similar to those at the TOA, but with smaller magnitudes. The relationship between SW CRF and CN concentration is complicated because other factors are at play, such as cloud phase, $\tau$, and cloud droplet size distribution. Aerosols could influence all cloud variables, but their influence is unclear. For a developing convective cloud system, the change in SW CRF is always negative because of the enhanced albedo effect. On the other hand, when mixed-phase clouds develop into mature DCCs, the cloud albedo effect easily saturates.

The relationship between net $\mathrm{CRF}$ and $\mathrm{CN}$ concentration follows the same pattern as that of the SW CRF at the top and bottom of the atmosphere because SW CRF is much larger in magnitude than LW CRF. The expansion of anvil sizes associated with the AIV produces more semi-transparent cirrus clouds, which could lead to a strong positive CRF.

$R_{\text {cloudy }}(\mathrm{SZA}, \mathrm{CN})$ at the TOA is a mean value obtained by averaging all cloudy pixels in a $20 \mathrm{~km} \times 20 \mathrm{~km}$ box centered on the SGP site. Changes in cloud coverage induced by the AIV are also taken into account. The competition between the cooling effect from the convective core and the warming effect from anvils in DCCs ultimately determines the sign of the net CRF induced by the AIV. Koren et al. (2010a) reached the same conclusion from model simulations of idealized tropical DCCs. In this regard, the observational findings presented here support their theoretical argument.
Figure 5 attempts to gain further insight into the two competing effects. DCCs were divided into thicker convective clouds (COD $>10)$, including deep but small convective cores, and thinner stratiform clouds $(\mathrm{COD}<10)$, including thin but extensive anvils, following Koren et al. (2010a). For simplicity, they are referred to as convective and core clouds (CCCs) and stratiform anvil clouds (SACs). Ideally, a DCC should be classified as a deep convective core associated with heavy precipitation, thick stratiform raining clouds, and thin non-precipitating clouds, as was done by Feng et al. (2011) following an integrative analysis of ground-based scanning radar and geostationary satellite data. A small subset of such DCC cases was identified at the SGP site during the 10-year period under study.

Figure 5 shows COD, cloud-top height, and CRF (SW, $\mathrm{LW}$, and net) as a function of $\mathrm{CN}$ concentration for CCCs and SACs. The COD associated with SACs remains constant as aerosol loading increases. The COD associated with CCC drops from 53.9 to 40.7 as $\mathrm{CN}$ concentrations increase from $1000 \mathrm{~cm}^{-3}$ to $5000 \mathrm{~cm}^{-3}$. This finding supports a new theory about the role of aerosols in the development of DCC (Fan et al., 2013). The conventional wisdom concerning the AIV (Rosenfeld et al., 2008a) is that by serving as CCN, more aerosol particles lead to smaller cloud droplets that are difficult to grow into raindrops, and thus are more likely to be elevated to above the freezing level. The release of additional latent heat further fuels convection to render clouds deeper and larger. This effect is referred to as the aerosol thermodynamic effect. Through extensive modeling and comparisons with observations, Fan et al. (2013) found that the thermodynamic effect plays an essential role in the initial stage of DCC development only. As a DCC enters into its mature and decaying stages, the aerosol microphysical effect becomes more dominant. Gravitational settling of a larger number of smaller ice crystals does not occur, so these ice crystals expand horizontally due to the capping near the upper troposphere and tropopause. During this process, more CCCs are transformed into SACs. This prevents the thickening of the $\mathrm{CCC}$ as the SAC, especially its anvil, spreads. As CN concentration increases from $1000 \mathrm{~cm}^{-3}$ to $5000 \mathrm{~cm}^{-3}$, the mean 


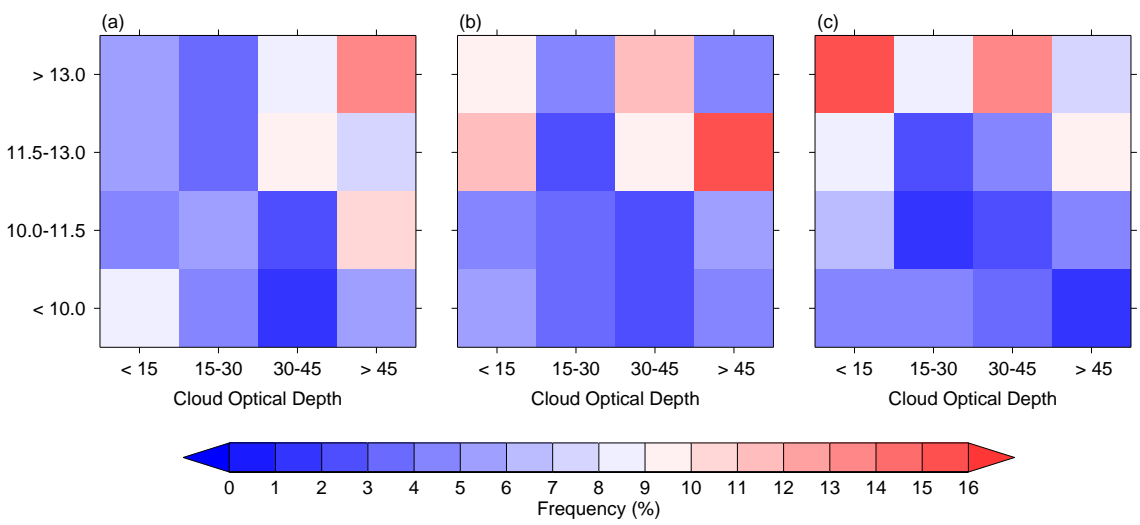

Figure 6. Cloud frequency of occurrence at three levels of CN concentration: (a) $0-2000 \mathrm{~cm}^{-3}$, (b) $2000-4000 \mathrm{~cm}^{-3}$, and (c) $4000-$ $6000 \mathrm{~cm}^{-3}$. Data are binned according to COD and cloud-top height.

cloud thickness averaged over the whole domain of $400 \mathrm{~km}^{2}$ increases from $10.3 \mathrm{~km}$ to $11.0 \mathrm{~km}$. As a result of the somewhat artificial division of $\mathrm{COD}=10$, the mean $\mathrm{COD}$ of the $\mathrm{CCC}$ decreases. However, this does not mean that cloud-top height decreases with increasing $\mathrm{CN}$. On the contrary, mean cloud-top heights for both CCCs and SACs increase with increasing $\mathrm{CN}$, and the rate of increase for SACs is more pronounced than that for CCCs. As the cloud expands horizontally, the cloud base is elevated, which is more significant for the SAC than for the CCC part of the DCC.

The elevation of SAC cloud-top heights leads to a LW warming effect. Decreases in COD and increases in CCC top height can lead to both SW and LW warming effects. Moreover, Fig. 1b illustrates that the areal coverage of SACs increases and the size of a given CCC shrink as the aerosol load increases, which could amplify the warming effect. For $\mathrm{SACs}$, as the CN concentration increases from $1000 \mathrm{~cm}^{-3}$ to $5000 \mathrm{~cm}^{-3}$, SW cooling decreases from $-206.9 \mathrm{Wm}^{-2}$ to $-135.9 \mathrm{Wm}^{-2}$, LW warming increases from $95.2 \mathrm{Wm}^{-2}$ to $122.4 \mathrm{Wm}^{-2}$, and the net effect is warming (Fig. 5c). Variations in SW and LW CRF for CCCs are more complicated, but the trend is generally warming, which is similar to what is shown in Fig. 4.

To further understand changes in CRF with changes in $\mathrm{CN}$ concentration, the frequency of cloud occurrence as a function of the COD and height $(Z)$, using GOES pixellevel $(4 \mathrm{~km})$ data, is examined (Fig. 6). In COD- $Z$ space, clouds grow taller and spread out at the top with lower optical depths, intensifying the warming effect. Under relatively clean conditions ( $\mathrm{CN}$ concentration: 0 to $2000 \mathrm{~cm}^{-3}$ ), frequencies of cloud occurrence greater than $10 \%$ (reddish color) occur when COD $>45$ and the cloud-top height is greater than $10 \mathrm{~km}$. Shifting to moderately polluted conditions (CN concentration: 2000 to $4000 \mathrm{~cm}^{-3}$ ), the largest frequency of cloud occurrence is in the bin with cloud-top heights between $11.5 \mathrm{~km}$ and $13.0 \mathrm{~km}$, and with COD $>45.0$, which indicates a well-developed convective core. The frequencies for bins with $\mathrm{COD}<15$ increase slightly and the overall altitudes of cloud-top height increase. This suggests that CCCs contribute the most to the CRF under moderately polluted conditions, even as the anvils are growing. Under heavily polluted conditions ( $\mathrm{CN}$ concentration: 4000 to $6000 \mathrm{~cm}^{-3}$ ), the largest frequency of cloud occurrence is in the bin with cloud-top heights greater than $13.0 \mathrm{~km}$, and with $\mathrm{COD}<15.0$. Grossly speaking, high $\mathrm{CN}$ concentrations are associated with the more frequent occurrence of higher and thinner SACs.

Over the SGP site, the frequency of occurrence of these kinds of mixed-phase warm-based clouds in different $\mathrm{CN}$ concentration bins ( 0 to $2000 \mathrm{~cm}^{-3}, 2000$ to $4000 \mathrm{~cm}^{-3}$ and greater than $\left.4000 \mathrm{~cm}^{-3}\right)$ is $36.4 \%, 38.1 \%$, and $25.4 \%$, respectively. Using clear-sky (CN concentration: 0 to $2000 \mathrm{~cm}^{-3}$ ) CRF as a baseline, TOA CRFs induced by the AIV are $8.69 \mathrm{Wm}^{-2}$ and $102.37 \mathrm{Wm}^{-2}$ under moderately and heavily polluted conditions, respectively. A rough estimate of daily mean TOA net CRF induced by the AIV is about $29.3 \mathrm{Wm}^{-2}$ (calculated by weighting CRFs by their corresponding frequencies of occurrence, i.e., $38.1 \% \cdot 8.69+25.4 \% \cdot 102.37)$. The daily mean surface net CRF induced by the AIV is $22.2 \mathrm{Wm}^{-2}$. The real climate impact of the AIV at this site is unknown because of the overall low frequency of occurrence of DCCs, which comprise $1.5 \%$ of all cloud types, according to long-term cloud statistics developed for the SGP site. Nevertheless, a warming effect offsetting the general cooling effect of the first aerosol indirect effect is observed.

\section{Conclusions}

Previous studies have shown that increasing aerosol loading increases the chance for warm-based mixed-phase clouds to develop into DCCs. This invigoration plays an important role in the hydrological cycle and on atmospheric general circulation through the release of latent heat which would modify atmospheric heating profiles and change the radiation 
budget of the climate system. The indirect effect of aerosols on clouds is the largest source of all uncertainties with regard to global climate forcing (IPCC, 2013). Small changes in cloud shape, structure, or lifetime can significantly change the local radiative balance.

This study is a systematic analysis of the AIV using a longterm, continuous ground-based data set of measurements from the ARM SGP site, together with GOES satellite-based retrievals, and a reanalysis data set. Results show that an increase in aerosol loading can invigorate convective clouds by increasing cloud-top heights, thicknesses, and the expansion of anvil cloud fractions when the atmosphere is unstable and moist. Weak wind shear promotes the lifting of cloud-top heights, but discourages anvil expansion as aerosol loading increases.

CRF of DCCs for different ranges of $\mathrm{CN}$ concentration are calculated by combining TOA radiative fluxes retrieved from GOES observations and simulated by a radiative transfer model. Cooling from the convective core and warming from the anvils are competing effects in DCCs. Whether the sign of the climate impact is negative or positive depends largely on the stage in the life cycle of the convective system. Over the SGP site, the long-term daily mean aerosolmediated TOA and surface CRF due to the AIV is positive in sign, and $29.3 \mathrm{Wm}^{-2}$ and $22.2 \mathrm{Wm}^{-2}$ in magnitude, respectively. This is based upon data from $\sim 300$ DCCs identified over a 10 -year period at the SGP site (about $1.5 \%$ of all clouds scenes occurring during this time).

The AIV on clouds is assessed using ground-based measurements, while cloud radiative forcing related to the AIV is calculated using an independent data set consisting of satellite retrievals and simulations from a radiative transfer model. Results from different approaches can support each other and corroborate the same phenomenon. Results of this study are robust and the quantified estimations of radiative forcing are valuable to weather and climate modeling. The method used in this study can be easily applied to data from other surface observatories in order to determine how the climate forcing of the AIV behaves for different cloud regimes.

Acknowledgements. This study has been supported under the National Key Program on Climate Change of MOST (2013CB955804, 2012CB955301), the Atmospheric System Research Program of the US Department of Energy (DESC0007171) and the National Science Foundation (1118325).

Edited by: Q. Fu

\section{References}

Ackerman, T. and Stokes, G.: The atmospheric radiation measurement program, Phys. Today, 56, 38-45, 2003.

Albrecht, B. A.: Aerosols, cloud microphysics, and fractional cloudiness, Science, 245, 1227-1230, 1989.

Andreae, M. O., Rosenfeld, D., Artaxo, P., Costa, A. A., Frank, G. P., Longo, K. M., and Silva-Dias, M. A. F.: Smoking rain clouds over the Amazon, Science, 303, 1337-1342, 2004.

Clothiaux, E. E., Ackerman, T. P., Mace, G. G., Moran, K. P., Marchand, R. T., Miller, M. A., and Martner, B. E.: Objective determination of cloud heights and radar reflectivities using a combination of active remote sensors at the ARM CART sites, J. Appl. Meteor., 39, 645-665, 2000.

Dong, X., Minnis, P., Mace, G. G., Smith Jr., W. L., Poellot, M., Marchand, R., and Rapp, A.: Comparison of stratus cloud properties deduced from surface, GOES, and aircraft data during the March 2000 ARM Cloud IOP, J. Atmos. Sci., 59, 3265- 3284, 2002.

Fan, J., Zhang, R., Li, G., and Tao, W-K.: Effects of aerosols and relative humidity on cumulus clouds, J. Geophys. Res., 112, D14204, doi:10.1029/2006JD008136, 2007.

Fan, J., Yuan, T., Comstock, J. M., Ghan, S., Khain, A., Leung, L. R., Li, Z., Martins, V. J., and Ovchinnikov, M.: Dominant role by vertical wind shear in regulating aerosol effects on deep convective clouds, J. Geophys. Res, 114, D22206, doi:10.1029/2009JD012352, 2009.

Fan, J., Rosenfeld, D., Ding, Y., Leung, Y. R., and Li, Z.: Potential aerosol indirect effects on atmospheric circulation and eadiative forcing through deep convection, Geophys. Res. Lett., 39, L09806, doi:10.1029/2012GL051851, 2012.

Fan, J., Leung, L. R., Rosenfeld, D., Chen, Q., Li, Z., Zhang, J., and Yan, H.: Microphysical effects determine macrophysical response for aerosol impact on deep convective clouds, P. Natl. Acad. Sci., 11, E4581-E4590, doi:10.1073/pnas.1316830110, 2013

Feng, Z., Dong, X., Xi, B., Schumacher, C., Minnis, P., and Khaiyer, M.: Top-of-atmosphere radiation budget of convective core/stratiform rain and anvil clouds from deep convective systems, J. Geophys. Res., 116, D23202, doi:10.1029/2011JD016451.1, 2011.

Freud, E., and Rosenfeld, D.: Linear relation between convective cloud drop number concentration and depth for rain initiation, J. Geophys. Res., 117, D02207, doi:10.1029/2011JD016457, 2012.

Huang, J., Minnis, P., Lin, B., Yi, Y., Khaiyer, M. M., Arduini, R. F., and Mace, G. G. : Advanced retrievals of multilayered cloud properties using multispectral measurements, J. Geophys. Res., 110, D15S18, doi:10.1029/2004JD005101, 2005.

IPCC: Climate Change 2013: The Physical Science Basis. Contribution of Working Group I to the Fifth Assessment Report of the Intergovernmental Panel on Climate Change, edited by: Stocker, T. F., Qin, D., Plattner, G.-K., Tignor, M., Allen, S. K., Boschung, J., Nauels, A., Xia, Y., Bex, V., and Midgley, P. M., Cambridge University Press, Cambridge, UK and New York, NY, USA, 1535 pp., 2013.

Khain, A. P. and Pokrovsky, A.: Simulation of effects of atmospheric aerosols on deep turbulent convective clouds using a spectral microphysics mixed-phase cumulus cloud model, Part II: Sensitivity study, J. Atmos. Sci., 61, 2983-3001, 2004. 
Khain, A. P., Pokrovsky, A., Pinsky, M., Seifert, A., and Phillips, V.: Effects of atmospheric aerosols on deep convective clouds as seen from simulations using a spectral microphysics mixedphase cumulus cloud model, Part 1: Model description, J. Atmos. Sci., 61, 2963-2982, 2004.

Khain, A. P., Rosenfeld, D., and Pokrovsky, A.: Aerosol impact on the dynamics and microphysics of deep convective clouds, Q. J. Roy. Meteor. Soc., 131, 2639-2663, doi:10.1256/qj.04.62, 2005.

Khain, A. P., BenMoshe, N., and Pokrovsky, A.: Factors determining the impact of aerosols on surface precipitation from clouds: an attempt at classification, J. Atmos. Sci., 65, 17211748, doi:10.1175/2007JAS2515.1, 2008.

Kollias, P., Tselioudis, G., and Albrecht, B. A.: Cloud climatology at the Southern Great Plains and the layer structure, drizzle, and atmospheric modes of continental stratus. J. Geophys. Res., 112, D09116, doi:10.1029/2006JD007307, 2007.

Koren, I., Kaufman, Y. J., Rosenfeld, D., ,Remer, L. A., and Rudich, Y.: Aerosol invigoration and restructuring of Atlantic convective clouds. Geophys. Res. Lett., 32, L14828, doi:10.1029/2005GL023187, 2005.

Koren, I., Remer, L. A., Altaratz, O., Martins, J. V., and David, A.: Aerosol-induced changes of convective cloud anvils produce strong climate warming, Atmos. Chem. Phys., 10, 5001-5010, doi:10.5194/acp-10-8855-2010, 2010a.

Koren, I., Feingold, G., and Remer, L. A.: The invigoration of deep convective clouds over the Atlantic: aerosol effect, meteorology or retrieval artifact?, Atmos. Chem. Phys., 10, 8855-8872, 2010 b.

Lazarus, S. M., Krueger, S. K., and Mace, G. G.: A Cloud Climatology of the Southern Great Plains ARM CART, J. Climate, 13, 1762-1775, doi:10.1175/15200442(2000)013<1762:ACCOTS>2.0.CO;2, 2000.

Li, Z. and Garand, L.: Estimation of surface albedo from space: A parameterization for global application, J. Geophys. Res., 99, 8335-8350, 1994.

Li, Z., Cribb, M., Chang, F. L., Trishchenko, A., and Yi, L.: Natural variability and sampling errors in solar radiation measurements for model validation over the Atmospheric Radiation Measurement Southern Great Plains region, J. Geophys. Res., 110, D15S19, doi:10.1029/2004JD005028, 2005.

Li, Z., Niu, F., Fan, J., Liu, Y., Rosenfeld, D., and Ding, Y.: Long-term impacts of aerosols on the vertical development of clouds and precipitation, Nat. Geosci., 4, 888-894, doi:10.1038/ngeo1313, 2011.

Liljegren, J. C.: Automatic self-calibration of ARM microwave radiometers, in: Microwave Radiometry and Remote Sensing of the Earth's Surface and Atmosphere, edited by: Pampaloni, P. and Paloscia, S., Lorton, VA, VSP Book, 433-443, 1999.

Lin, J. C., Matsui, T., Pielke Sr., R. A., and Kummerow, C.: Effects of biomass-burning-derived aerosols on precipitation and clouds in the Amazon Basin: A satellite-based empirical study, J. Geophys. Res., 111, D19204, doi:10.1029/2005JD006884, 2006.

Min, Q. and Harrison, L. C.: Cloud properties derived from surface MFRSR measurements and comparison with GOES results at the ARM SGP site, Geophys. Res. Lett., 23, 1641-1644, doi:10.1029/96GL01488, 1996.

Min, Q., Joseph, E., and Duan, M.: Retrievals of thin cloud optical depth from a multifilter rotating shadowband radiometer, J. Geophys. Res., 109, D02201, doi:10.1029/2003JD003964, 2004.
Min, Q., Wang, T., Long, C. N., and Duan, M.: Estimating fractional sky cover from spectral measurements, J. Geophys. Res., 113, D20208, doi:10.1029/2008JD010278, 2008.

Minnis, P., Smith, Jr., W. L., Garber, D. P., Ayers, J. K., and Doelling, D. R.: Cloud properties derived from GOES-7 for Spring 1984 ARM intensive observing period using version 1.0.0 of ARM satellite data analysis program, NASA RP 1366, p. 58, 1995.

Minnis, P., Sun-Mack, S., Young, D. F., Heck, P. W., Garber, D. P., Chen, Y., Spangenberg, D. A., Arduini, R. F., Trepte, Q. Z.. Smith, Jr. W. L., Ayers, J. K., Gibson, S. C., Miller, W. F., Chakrapani, V., Takano, Y., Liou, K.-N., Xie, Y., and Yang P.: CERES Edition-2 cloud property retrievals using TRMM VIRS and Terra and Aqua MODIS data, Part I: Algorithms, IEEE Trans. Geosci. Remote Sens., 49, 4374-4400, 2011.

Niu, F. and Li, Z.: Systematic variations of cloud top temperature and precipitation rate with aerosols over the global tropics, Atmos. Chem. Phys., 12, 8491-8498, doi:10.5194/acp-12-84912012, 2012.

Ricchazzi, P., Yang, S. R., Gautier, C., and Sowle, D.: SBDART: A research and teaching software tool for plane-parallel radiative transfer in the earth's atmosphere, B. Am. Meteor. Soc., 79, 2101-2114, 1998.

Rosenfeld, D., Kaufman, Y., and Koren, I.: Switching cloud cover and dynamical regimes from open to closed Benard cells in response to aerosols suppressing precipitation, Atmos. Chem. Phys., 6, 2503-2511, doi:10.5194/acp-6-2503-2006, 2006.

Rosenfeld. D., Lohmann, U., Rage, G. B., O’Dowd, C. D., Kulmala, M., Fuzzi, S., Reissell, A., and Andreae, M. O.: Flood or drought: How do aerosols affect precipitation?, Science, 321, 1309-1313, 2008a.

Rosenfeld, D., Woodley, W. L., Axisa, D., Freud, E., Hudson, J. G., and Givati, A.: Aircraft measurements of the impacts of pollution aerosols on clouds and precipitation over the Sierra Nevada, J. Geophys. Res., 113, D15203, doi:10.1029/2007JD009544, 2008b.

Rosendeld D., Wood R., Donner, L., Sherwood S.: Aerosol cloudmediated radiative forcing: highly uncertain and opposite effects from shallow and deep clouds, Springer Press, 105-149, 2013.

Seifert, A., and Beheng, K. D.: A two-moment cloud microphysics parameterization formixed-phase clouds, Part 2: Maritime vs. continental deep convective storms, Meteorol. Atmos. Phys., 92, 67-82, 2006.

Stokes, G. M. and Schwartz, S. E.: The Atmospheric Radiation Measurement (ARM) program: Programmatic background and design of the cloud and radiation testbed, Bull. Am. Meteorol. Soc., 75, 1201-1221, 1994.

Storer, R. L., van den Heever, S. C., and Ecuyer, T. S. L.: Observations of aerosol-induced convective invigoration in the tropical east Atlantic, J. Geophys. Res. Atmos., 119, 1-13, doi:10.1002/2013JD020272, 2014.

Tao, W.-K., Chen, J. P., Li, Z.,Wang, C., and Zhang, C.: Impact of aerosols on convective clouds and precipitation, Rev. Geophys., 50, RG2001, doi:10.1029/2011RG000369, 2012.

Twomey, S.: The influence of pollution on the shortwave albedo of clouds, J. Atmos. Sci., 34, 1149-1152, 1977.

van den Heever, S. C., Carrio', G. G., Cotton, W. R., Demott, P. J., and Prenni, A. J.: Impact of nucleating aerosol on Florida 
storms, part 1: mesoscale simulations, J. Atmos. Sci, 63, 17521775, 2006.

van den Heever, S. C., Stephens, G. L., and Wood, N. B.: Aerosol indirect effects on tropical convection characteristics under conditions of radiative-convective equilibrium, J. Atmos. Sci., 68, 699-718, 2011.

Wang, C.: A modeling study of the response of tropical deep convection to the increase of cloud condensation nuclei concentration, 1. Dynamics and microphysics, J. Geophys. Res., 110, D21211, doi:10.1029/2004JD005720, 2005.

Wang, T. and Min, Q.: Retrieving optical depths of optically thin and mixed-phase clouds from MFRSR measurements, J. Geophys. Res., 113, D19203, doi:10.1029/2008JD009958, 2008.

Williams, E., Rosenfeld, D., Madden, N., Gerlach, J., Gears, N., Atkinson, L., Dunnemann, N., Frostrom, G., Antonio, M., Biazon, B., Camargo, R., Franca, H., Gomes, A., Lima, M., Machado, R., Manhaes, S., Nachtigall, L., Piva, H., Quintiliano, W., Machado, L., Artaxo, P., Roberts, G., Renno, N., Blakeslee, R., Baiey, J., Boccippio, D., Betts, A., Wolff, D., Roy, B., Halverson, J., Rickenbach, T., Fuentes, J., and Avelino, E.: Contrasting convective regimes over the Amazon: Implications for cloud electrification, J. Geophys. Res., 107, 8082, doi:10.1029/2001JD000380, 2002.
Yan, H. R., Huang, J., Minnis, P., Wang, T., and Bi, J.: Comparison of CERES surface radiation fluxes with surface observations over Loess Plateau, Remote Sens. Environ., 115, 1489-1500, 2011.

Yuan, T., Remer, L. A., Pickering, K. E., and Yu, H.: Observational evidence of aerosol enhancement of lightning activity and convective invigoration, Geophys. Res. Lett., 38, L04701, doi:10.1029/2010GL046052, 2011. 